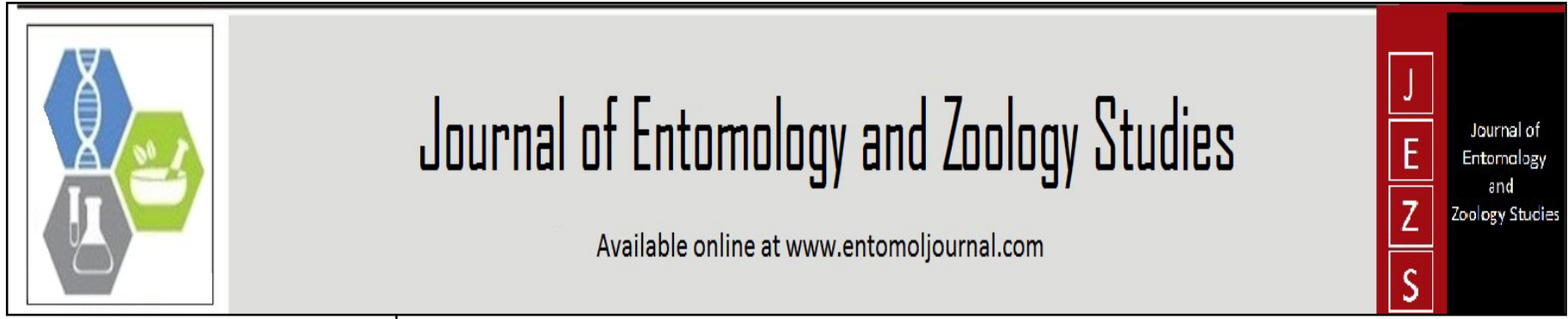

E-ISSN: 2320-7078

P-ISSN: 2349-6800

JEZS 2016; 4(3): 86-87

(C) $2016 \mathrm{JEZS}$

Received: 08-03-2016

Accepted: 09-04-2016

\section{Mark Ian Cooper}

Department of Biological

Sciences, Faculty of Science,

Private Bag X3, Rondebosch

7701, South Africa.

\section{Correspondence}

Mark Ian Cooper

Department of Biological

Sciences, Faculty of Science,

Private Bag X3, Rondebosch

7701, South Africa.

\title{
Sexual bimaturism in the millipede Centrobolus inscriptus Attems (Spirobolida: Trigoniulidae)
}

\section{Mark Ian Cooper}

\section{Abstract}

Millipedes have determinate growth and adult body sizes are fixed. In the sexually size dimorphic genus Centrobolus intergenerational sexual differences in body size was examined in a population of $C$. inscriptus. Millipedes were measured with minimum measurement error and volumetric body size calculated according to $l . \pi . r^{2}$. Four male and five female stadia were detected in the population and figured. One evolutionary explanation for the extra female stage is fecundity selection for larger female size. This is preliminary evidence for sexual bimaturism in arthropods.

Keywords: allometry, bimaturism; Centrobolus, body size, diplopod, millipede, stadia

\section{Introduction}

Millipedes have asymptotic or determinate growth which means that adult body sizes are fixed and can be measured with minimum error ${ }^{[1-2]}$. Centrobolus millipedes follow Rensch's Rule because females are larger than males and regression in this dimorphism increase with size on a slope or gradient of 0.85 which is less than $1.0^{[3]}$. Proximate causes for sexual dimorphism are sexual bimaturism and fecundity selection ${ }^{[4-5]}$. There is overwhelming evidence for fecundity selection which maintains there is an age-specific force of natural selection. Little evidence exists for sexual bimaturism. The pattern of stadia in a population of the millipede $C$. inscriptus was examined. The null hypothesis was that there is no difference in the number of male versus female stadia.

\section{Materials and Methods}

Millipedes were hand sampled from a population of Centrobolus inscriptus at Twin Streams Farm (28 $55^{\prime} \mathrm{S} ; 31^{\circ} 45^{\prime} \mathrm{E}$ ) during the rainy season (1996). Males and females were measured in the same manner using the same scale so that both measurement and intrinsic errors were alike for both sexes. Body length $(\mathrm{mm})$ and width $(\mathrm{mm})$ were measured with vernier scale calipers, mass (accurate to $0.01 \mathrm{~g}$ ) taken by placing animals directly on a Mettler balance, for all the males and females. Size was perceived as body volume by using the formula for a cylindrical bauplan: $l . \pi . r^{2}$; where $l$ is the length and $r$ the radius of the cylinder.

\section{Results}

Separate stadia were identified based originally on length and width for each sex in $C$. inscriptus. C. inscriptus females have an extra stadia compared to males. Four male and five female stadia were detected in the population (Figure 1). The additional female stages were evident as the final two adult stadia, which were larger than $2300 \mathrm{~mm}^{3}$. A single large male was found in this population.

\section{Discussion}

There was a difference between the numbers of male versus female stadia in $C$. inscriptus (Figure 1). Female Julida millipedes live longer and undergo more moults, and hence attain more segments and a larger diameter than males ${ }^{[4]}$. Significant size differences exist between species in a community, and also between different stadia of a species of European millipedes $[5,6]$. The extra female stadia in the $C$. inscriptus population supports sexual bimaturism and fecundity selection ${ }^{[4,7]}$. Also the evidence would support sexual bimaturism if maturity is reached by stadia III in C. inscriptus. This finding appears similar to the pattern in the lifehistory of the millipede Nopoiulus kochii ${ }^{[8]}$. It differs from the life history of Cylindroiulus spp. and thus is not consistent among all Julidan millipedes ${ }^{[9]}$. This is preliminary evidence for sexual bimaturism. 


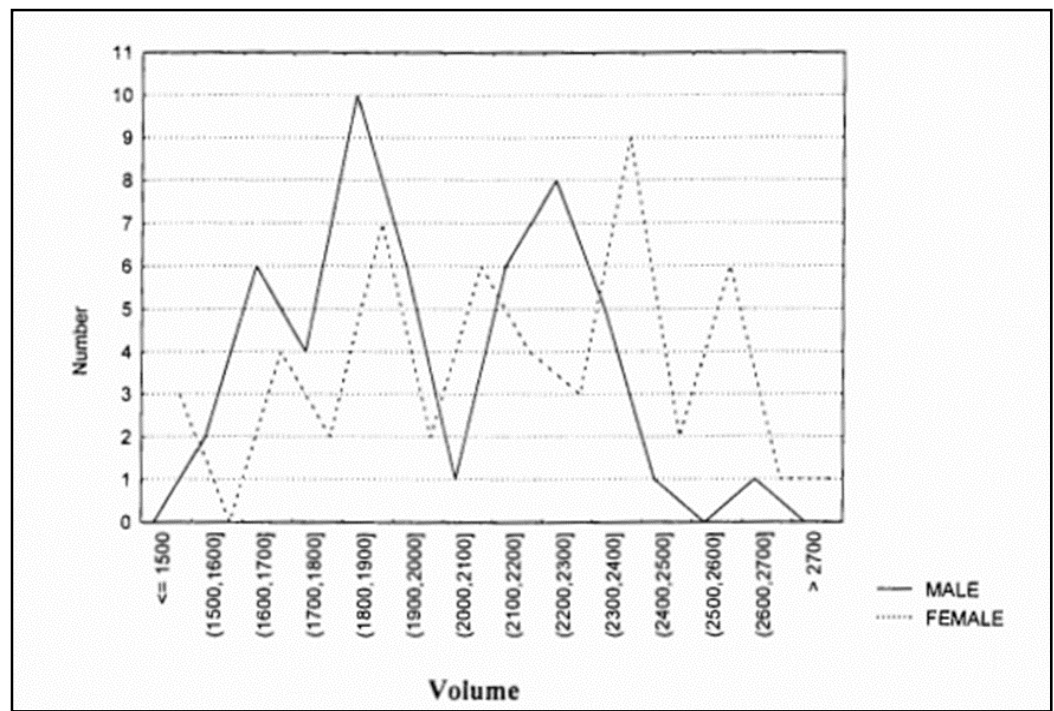

Fig 1: The sexual differences in the distribution of body volumes $\left(\mathrm{mm}^{3}\right)$ calculated for the millipede Centrobolus inscriptus from a population sampled during the mating season.

\section{Conclusion}

Differences in the number of male and female stadia in $C$. inscriptus provide preliminary evidence for sexual bimaturism under Rensch's Rule in arthropods.

\section{References}

1. Hopkin SP, Read HJ. The Biology of Millipedes. Oxford University Press, 1992, 223.

2. Cooper MI. Sex ratios, mating frequencies and relative abundance of sympatric millipedes in the genus Chersastus (Diplopoda: Pachybolidae). Arthropods 2014a; 3(4):174-176.

3. Cooper MI. Sexual size dimorphism and corroboration of Rensch's rule in Chersastus millipedes (Diplopoda: Pachybolidae). Journal of Entomology and Zoology Studies. 2014b; 2(6):264-266.

4. Blanckenhorn WU, Dixon AFG, Fairbairn DJ, Foellmer MW, Gibert P, Van der Linde K et al. Proximate Causes of Rensch's Rule: Does Sexual Size Dimorphism in Arthropods Result from Sex Differences in Development Time? The American Naturalist 2007; 169(2):245-257.

5. Read HJ. The life histories of millipedes, a review of those found in British species of the order Julida and comments on endemic Maderian Cylindroiulus species. Revue d'Ecologie et de Biologie du Sol 1989; 25:451-467.

6. Kime RD. Spatio-temporal distribution of European millipedes. In: Minelli A (ed.): Proceedings of the 7th International Congress of Myriapodology, E.J. Brill, Leiden, 1990, 367-380.

7. Enghoff H. The Size of a Millipede. Proceedings of the 8th International Congress of Myriapodology, Innsbruck, Austria, 1990, 47-56.

8. Telford SR, Dangerfield JM. Sexual selection in millipedes: Pattern, product and process. In: Geoffroy J-J, Mauriès J-P, Nguyen Duy - Jacquemin M (eds.), Acta Myriapodologica. Memoires du Museum national d'Histoire naturelle 1996; 169:565-576.

9. Kheirallah A-M, Aly A-NH, Abdel-Wahed NY. Anamorphosis and life-history of the millipede Nopoiulus kochii (Gervais, 1847), new for Egypt. Zoology in the Middle East 2000; 21(1):159-168.

10. David J-F. Size criteria for the distinction between Cylindroiulus londinensis (Leach) and Cylindroiulus caeruleocinctus (Wood) (Diplopoda: Julidae). Journal of
Natural History. 1995; 29(4):983-991. 